Original article

\title{
Do clinical characteristics predict the cognitive course in early-onset schizophrenia-spectrum disorders?
}

Charlotte M. Teigset (a*), Christine Mohn (a), Cathrine Brunborg (c), Monica Juhl-Langseth (b), Aina Holmén (b), Bjørn Rishovd Rund (a,b)

a. Vestre Viken Hospital Trust, Research Department, Wergelands gate 10, 3004 Drammen, Norway

b. Department of Psychology, University of Oslo, Postboks 1094 Blindern, 0317 Oslo, Norway

c. Oslo University Hospital, Research Support Unit, Postboks 4950 Nydalen, 0424 Oslo

*Corresponding author:

Charlotte M. Teigset

Vestre Viken Hospital Trust, Research Department

Wergelands gate 10

3004 Drammen

Norway

Phone: +47 40288443

Fax: +47 22845001

E-mail: charlotte.teigset@psykologi.uio.no; cteigset@hotmail.com

Co-authors: b.r.rund@ psykologi.uio.no; h.c.mohn@psykologi.uio.no;

cathrine.brunborg@ous-hf.no; aina.holmen@psykologi.uio.no; monica@nyetanker.no

Running head: Clinical variables and cognitive course in EOS

Words count: 5485 words 


\section{Abstract}

Background: Being in a period with extensive brain maturation, adolescents with early-onset schizophrenia-spectrum disorders (EOS) provide unique neurodevelopmental data that may contribute to a better understanding of schizophrenia at all ages. Cognitive dysfunction is a central feature of schizophrenia and is more pronounced in EOS than in later onset illness. However, there is limited research on both the long-term course of global cognition in EOS, and how cognition over time is influenced by clinical characteristics during the early illness period.

Methods: Thirty-one EOS patients and 73 controls (age 12-18) were assessed on clinical variables at baseline (PANSS, duration of untreated psychosis [DUP], hospitalizations, suicide attempts and remission). Neuropsychological assessments with the MATRICS Consensus Cognitive Battery (MCCB) were conducted at baseline, after both one and two years, and composite scores of total performance were calculated. The analyses were performed with a linear mixed model.

Results: The present study suggested that global cognition followed a stable course over the first years of the disease in EOS, though at a significantly lower level in EOS compared to the controls. We did not detect a relationship between DUP, remission, positive/negative symptoms and hospitalizations on the one hand, and long-term cognition on the other, but PANSS-general and suicide attempt history at baseline were identified as risk factors of longitudinal cognitive function.

Conclusions: Though at different levels, the EOS group and the controls had a similar cognitive course over two years. Some baseline characteristics (psychotic symptoms, DUP, remission and hospitalization) had no influence on cognition within the first two years of 
illness. In contrast, general symptoms and a history of suicide attempts at baseline were more potent risk factors of the cognitive course than the psychotic-specific symptoms, and should therefore be subject to specific attention in the evaluation and treatment of patients with early onset psychosis.

Keywords: cognition, early-onset schizophrenia, suicide attempts, general symptoms 


\section{Introduction}

A major objective in schizophrenia research is to find reliable prognostic factors that may help identify therapeutic targets and allocate resources to those with the greatest needs. Approximately $5 \%$ of the schizophrenia population has an illness onset before 18 years of age, which is often referred to as early-onset schizophrenia-spectrum disorders (EOS) (Cannon et al., 1999). Research suggests that EOS reflects increased disease severity, with a worse clinical course and outcome (Remschmidt et al., 2007; Schimmelmann, Conus, Cotton, McGorry, \& Lambert, 2007). The cognitive profile in EOS seems to be similar to adult-onset schizophrenia (AOS) (Holmen, Juuhl-Langseth, Thormodsen, Melle, \& Rund, 2010; Kravariti, Morris, Rabe-Hesketh, Murray, \& Frangou, 2007; Oie, Sundet, \& Ueland, 2011), but more impaired (Jepsen et al., 2013; Nieto \& Castellanos, 2011; Rajji, Ismail, \& Mulsant, 2009), and with a more pronounced developmental and premorbid anomaly (Frangou, 2013; Kumra \& Charles Schulz, 2008; Teigset, Mohn, \& Rund, 2016). EOS patients develop symptoms in a period with extensive brain maturation and alterations in cognitive structures and functions (Juuhl-Langseth, Holmen, Thormodsen, Oie, \& Rund, 2014); thus, they provide unique neurodevelopmental data that may contribute to a better understanding of schizophrenia at all ages (Bombin et al., 2013; Rapoport, Giedd, \& Gogtay, 2012; Remschmidt, 2002).

Although cognitive deficits do not appear in all cases (Rund, Zeiner, Sundet, Oie, \& Bryhn, 1998), they are considered to be a core feature of schizophrenia (Palmer, Dawes, \& Heaton, 2009; Rund et al., 2006; Torgalsboen, Mohn, \& Rishovd Rund, 2014; Townsend \& Norman, 2004), and are more pronounced in schizophrenia than in bipolar disorders (Landro, Orbeck, \& Rund, 1993; Seidman et al., 2013). While some studies argue for specific deficits, others suggest deficiencies across the cognitive domains (Christensen et al., 2014; Jepsen et 
al., 2013; Kravariti, Morris, Rabe-Hesketh, Murray, \& Frangou, 2003b; Mesholam-Gately, Giuliano, Goff, Faraone, \& Seidman, 2009; Nieto \& Castellanos, 2011; Rajji et al., 2009). A number of comprehensive meta-analyses from both chronic and first-episode schizophrenia suggest that essentially all cognitive domain are affected, with most effect sizes ranging from moderate to large (Heinrichs \& Zakzanis, 1998; Mesholam-Gately et al., 2009), and that the deficiencies are consistent over decades and across cultures (Schaefer, Giangrande, Weinberger, \& Dickinson, 2013). A natural consequence of this has been a more frequent use of composite scores in cognitive studies of schizophrenia (Meyer et al., 2014; Rund et al., 2015).

The trajectories of cognitive deficits over the course of the disease are being debated, and one question has been whether schizophrenia involves neurodegeneration (Rund, 2009). To date, most longitudinal studies indicate a stable cognitive course in AOS (Bora, 2015; Rund et al., 2015), with a growing body of research suggesting a similar stability in EOS (Bombin et al., 2013; Frangou, Hadjulis, \& Vourdas, 2008; Jepsen, Fagerlund, Pagsberg, Christensen, Nordentoft, et al., 2010; Juuhl-Langseth et al., 2014; Mayoral et al., 2008; Oie, Sundet, \& Rund, 2010). However, the course of global cognition over the first years, as measured in composite scores, has yet to be reported in EOS. A further objective is to identify factors affecting the cognitive course. While both cognition and clinical variables have been subject to comprehensive research in schizophrenia, the interaction between the two has gained less attention, especially in EOS. An essential question is to what extent the longitudinal course of cognition is influenced by clinical characteristics in the early illness period.

Previous research from AOS diverges on the association between psychotic symptoms and cognition, both at baseline (Harvey, Green, Bowie, \& Loebel, 2006; Rund et 
al., 2004; Ventura, Thames, Wood, Guzik, \& Hellemann, 2010) and longitudinally (Bagney et al., 2015; Barder et al., 2013; Fervaha, Foussias, Agid, \& Remington, 2014; Hoff et al., 1999; Mayer, 2002; Meier et al., 2014; Rund et al., 2015). Research that examines baseline correlations suggests that negative symptoms interact with cognition to a greater extent than positive symptoms (Bora, Yucel, \& Pantelis, 2009; Kravariti et al., 2012; O'Connor et al., 2013), with one long-term study reporting that negative symptoms may help mediate the relationship between cognition and functioning (Meyer et al., 2014). Other longitudinal findings report associations between a reduction in positive symptoms and cognitive improvement (Hoff et al., 1999), or a small to no relationship between positive/negative symptoms and cognition (Rund et al., 2004).

Research on youths with bipolar disorder indicates increased cognitive deficits due to symptom severity and psychotic features (Arango, Fraguas, \& Parellada, 2014; Fitzgerald et al., 2004; McCarthy, Weiss, Segovich, \& Barbot, 2016; Udal et al., 2013). In youths with schizophrenia-spectrum disorders, we find only one study that has investigated the long-term interaction between psychotic symptoms and cognition (Wozniak, Block, White, Jensen, \& Schulz, 2008). They found no association between cognition and psychotic symptoms, with the exception of a lower IQ predicting more negative symptoms after one year. However, their study had a short follow-up period and other clinical characteristics were not examined, thereby raising questions about the relationship between a wider range of symptoms and cognition, in addition to whether the deterioration endures over time. Furthermore, the disappearance of psychotic symptoms may also affect long-term cognition, although the relationship between remission and cognition has yet to be investigated in EOS. Nevertheless, in an adult sample, Rund et al. (2015) found that a stable remission without relapse in the first year seemed to predict a better cognitive course. 
Another relevant clinical variable is illness duration. The "neurotoxicity-hypothesis" suggests that a longer duration of untreated psychosis (DUP) accelerates cognitive deterioration (Wyatt, 1991). In adult samples, some longitudinal studies report that a shorter DUP leads to a better overall cognitive functioning (Cuesta et al., 2012; Dominguez et al., 2013; Yamazawa et al., 2008), but the majority of studies report no such association (Goldberg et al., 2009; Melle et al., 2008; Rund, 2014; Rund et al., 2015; Rund et al., 2007). Research on the interaction between DUP and cognition in EOS is rare. One baseline study found no immediate effect of illness duration on cognitive performance in EOS (Kravariti, Morris, Rabe-Hesketh, Murray, \& Frangou, 2003a), while another longitudinal study found that a shorter illness duration was associated with a greater improvement in executive functions after two years (Fraguas et al., 2014). Whereas the majority of AOS studies reported no association between DUP and cognitive course (Goldberg et al., 2009; Melle et al., 2008; Rund et al., 2015; Rund et al., 2007), the findings of Fraguas et al. (2014) suggest a possibly worse impact of DUP on cognition in EOS compared with AOS.

A final research question concerns the relationship between non-psychotic symptoms and cognition. About half of all schizophrenia patients attempt suicide, and 9-13\% ultimately do commit suicide (Potkin, Anand, Alphs, \& Fleming, 2003), as depression and insight seem to be important predictors (Hor \& Taylor, 2010). Even so, little is known about the relationship between suicidality and cognition in EOS, and results are inconsistent in AOS; some indicate an association between a higher cognitive function and a history of suicide attempts, while others find no such association (Delaney et al., 2012; Kim, Jayathilake, \& Meltzer, 2003; Potkin et al., 2003; Zoghbi et al., 2014).

If clinical characteristics at baseline can predict the cognitive course in EOS, this is essential for prognosis and therapy. In the present study, we first report how the cognitive 
composite score develops over time in EOS, compared to healthy controls. However, the primary aim of this paper is to investigate to what extent the cognitive course in EOS is influenced by clinical characteristics during the early illness period, such as symptoms of schizophrenia, DUP, remission, suicide attempts and number and duration of hospitalizations caused by psychosis.

\section{Method}

Some assessments of the longitudinal trajectory in the current EOS group have already been reported (Juuhl-Langseth et al., 2014), and revealed stable deficits in all cognitive domains, with the exception of working memory and processing speed. Because of drop-outs, only $65 \%$ of the patients were included in the analyses at the last time point. In the present study, we analyzed cognitive composite scores and used statistical analyses (linear mixed model) that allow the inclusion of all participants with at least one neurocognitive evaluation.

\section{Subjects}

The current paper is part of the Early-onset Study, a longitudinal study carried out at the University of Oslo. Patients were consecutively recruited between 2005 and 2009, and were tested three times; at baseline, after one year and after two years (Holmen et al., 2010; JuuhlLangseth et al., 2014; Thormodsen, Juuhl-Langseth, Holmen, \& Rishovd Rund, 2012). The patients were recruited from various inpatient and outpatient units in Eastern Norway, and inclusion criteria were age (12-18 years) and the diagnosis of schizophrenia spectrum disorder according to DSM-IV. Exclusion criteria were central nervous system pathology, head injury (loss of consciousness for more than 30 minutes and/or any neurological sequelae), or an estimated IQ of less than 70 . 
A total of 31 patients were included at baseline (T1), and schizophrenia-spectrum disorders describe the whole sample, with a diagnosis of schizophrenia: $\mathrm{n}=17(54.9 \%)$ (including paranoid schizophrenia, catatonic schizophrenia, schizophrenia undifferentiated and residual schizophrenia), schizophreniform psychosis: $\mathrm{n}=1$ (3.2\%), schizoaffective disorders: $n=3(9.7 \%)$ and psychosis not otherwise specified (NOS): $n=10(32.3 \%)$. The percentage distribution of diagnoses stayed relatively stable; after one year (T2), 55\% $(n=12)$ were diagnosed with schizophrenia), $14 \%(n=3)$ with schizoaffective disorders and $18 \%(n=4)$ with psychosis NOS. After two years (T3), 55\% $(n=11)$ of the EOS patients were diagnosed with schizophrenia, $20 \%(\mathrm{n}=4)$ with schizoaffective disorders and $10 \%(\mathrm{n}=2)$ with psychosis NOS. Three patients had no diagnoses at T3, two of whom had psychosis NOS, and one residual schizophrenia at baseline. At $\mathrm{T} 1,74 \%$ of the patients received antipsychotic medication, $41 \%$ of them were medicated at $\mathrm{T} 2$ and $50 \%$ at $\mathrm{T} 3$. At $\mathrm{T} 1$, all received secondgeneration antipsychotic medication (Quetiapine $(n=5)$, Risperdone (n=3), Ziprasidone $(n=3)$, Aripiprazole $(n=4)$, Olanzapine $(n=7)$ and Clozapine $(n=1))$, three in combination with firstgeneration anti-psychotics, four in combination with anti-depressants, two in combination with benzodiazepines and one in combination with mood stabilizers. Calculated daily doses (CDD) (WHO, 2010) in mean at T1 was 1.2, at T2 1.5 and at T3 1.4 for antipsychotic medication. CDD of medication were based on the international daily dose of medication technical measurement system (WHO, 2010), where the CDD is the outcome of the prescribed daily dose divided by the average recommended daily dose of medication. The results were previously reported by Juuhl-Langseth et al. (2014), who found no significant change in CDD over time, and no relationship between medication and cognitive performance. The mean age of the EOS group was 15.6 years at baseline. No deaths occurred in our sample in the timeframe measured. 
The healthy controls (HC) were randomly selected from the Norwegian population register and contacted by letter, or they were contacted through advertisements at four schools in Eastern Norway. They were all matched to patients on gender, age and length of education. All patients and $\mathrm{HC}$ attended regular school classes at normal grade levels. The HC was screened for mental problems using the Mini-International Neuropsychiatric Interview (M.I.N.I.) screening module (Sheehan et al., 1998), and were excluded from the study when disqualified by the screening criteria.

A total of 31 patients and 73 healthy controls were included at baseline and were followed longitudinally. The number of participants who attended the study at T2/T3 was: EOS 22/20, and controls 41/40, and the participants who completed all the tests included in the composite score were 29 patients at T1, 18 at $\mathrm{T} 2$ and 18 at $\mathrm{T} 3$ in the EOS group, in the control group there were 67 participants at T1, 39 at T2 and 40 at T3.

Table 1 Demographic and clinical characteristics for EOS patients and healthy controls at baseline

\begin{tabular}{llll} 
& $\mathrm{EOS}(N=31)$ & $\mathrm{HC}(N=73)$ & Test statistics \\
\hline Age in years (SD) & $15.8(2.0)$ & $15.8(2.0)$ & $\mathrm{ns}$ \\
$\begin{array}{l}\text { Gender, male/female, } N(\%) \\
16 / 15(52 / 48)\end{array}$ & $35 / 38(48 / 52)$ & $\mathrm{ns}$ \\
Handedness, r/l, $N(\%)$ & $27 / 4(87 / 13)$ & $67 / 6(92 / 8)$ & $\mathrm{ns}$ \\
IQ* (SD) & $97.1(14.6)$ & $108.5(14.1)$ & $\mathrm{t}(102)=-3.72^{* * * *}$ \\
$\begin{array}{l}\text { Mean length of mothers } \\
\text { education in years (SD) }\end{array}$ & $13.3(2.9)$ & $15.2(2.8)$ & $\mathrm{t}(101)=-3.20^{* *}$ \\
$\begin{array}{l}\text { Mean length of fathers } \\
\text { education in years (SD) }\end{array}$ & $13.6(3.0)$ & $14.8(2.8)$ & $\mathrm{ns}$ \\
$\begin{array}{l}\text { Mean duration of illness in } \\
\text { years (SD) }\end{array}$ & $1.7(1.4)$ & & \\
$\begin{array}{l}\text { Mean DUP in weeks } \\
\text { (1) }\end{array}$ & $35.0(1-208)$ & &
\end{tabular}


(range)

Patients who have

attempted to commit suicide

(1-5 times), $N(\%)$

Number of times in

hospital, median (range)

Patients with remission, $N \quad 10(34.5)$

$(\%)$

*Wechslers Abbreviated Scale of Intelligence, full scale IQ. *** $p<.001 . * * p<.01$

All participants were given a complete description of the study, and written informed consent was obtained from both the patients and their parents, if the participant was younger than 16. The study was also approved by the Regional Committee for Medical Research Ethics (REK Sør-Øst) and the Norwegian Data Inspectorate.

\section{Clinical assessments}

The clinical and cognitive assessments were carried out by trained clinical psychologists. All baseline tests were performed within eight weeks after inclusion in the study. Diagnostic evaluations were based on the Structured Clinical Interview for DSM-IV Axis I Disorders (SCID-I), modules A-D. The interviewers participated in regular diagnostic consensus meetings led by well-experienced clinical researchers, and completed the training course in SCID assessment arranged by the University of California, Los Angeles (UCLA). The mean overall kappa as assessed in the UCLA training course was 0.77 (Holmen et al., 2010).

For the assessment of psychotic symptoms and functioning, the Positive and Negative Syndrome Scale (PANSS) (Kay, Fiszbein, \& Opler, 1987) was used, and we calculated the PANSS baseline scores for the positive, negative and general component. The age of onset was defined by a PANSS score of 4 or more on the Positive or General Scale (see DUP), and 
the mean age of onset in the group was 14 years (range 10-17). Moreover, only baseline scores were used in the analyses. However, Juuhl-Langseth et al. (2014) previously reported stability in symptom levels over the three time points and found no significant changes over time in positive, negative or general symptoms, thereby securing that the baseline group did not differ significantly from those who participated at T2 and T3. Global functioning was measured at baseline with the Global Assessment of Functioning-Split version (Split-GAF) (Pedersen, Hagtvet, \& Karterud, 2007). As in the symptom scales, there were no significant changes in split-GAF (symptoms or function) from T1 to T3 (mean at T1/T2/T3; symptoms 47.5/54.3/58.4, function 47.8/58.1/58.2).

DUP was measured by the time interval from the first onset of psychotic symptoms; defined as the first week with a PANSS score of 4 or more on one of the Positive Scale items 1 (delusions), 3 (hallucinatory behavior), 5 (grandiosity), 6 (suspiciousness/persecution), or General Scale item 9 (unusual thought content) to the start of the first adequate treatment of psychosis (defined as the start of adequate antipsychotic medication or admission to the hospital for treatment).

Suicide attempts were assessed in the clinical interviews by asking the youths if they had ever attempted to kill themselves, and if yes, how many times. As reported by the patients, the total number of suicide attempts before baseline was recorded. In the group of 31 patients, $6.7 \%$ reported one suicide attempt, $10 \%$ had two attempts, $3.3 \%$ had three attempts and $3.3 \%$ had five attempts.

Hospitalization was measured by the number of times a patient was admitted to psychiatric inpatient treatment due to psychotic symptoms before baseline assessment. The total length of inpatient treatment was measured in weeks, while the mean length of hospitalization in the group was 28.7 weeks (range 0-138). 
Remission was defined by the disappearance of psychotic symptoms for at least seven days before baseline, as defined by the same PANSS symptoms as defined in DUP (see above). Of those in remission, 20\% were in remission for seven days, $10 \%$ for 14 days, whereas $70 \%$ were in remission for 8-17 weeks.

All the clinical characteristics were measured only once (T1). Among the potential risk factors (PANSS, DUP, number of times on hospital, remission, suicidality), PANSS had three missing values, suicidality had one missing value, and remission had two missing values.

\section{Neuropsychological assessments}

All participants were tested with the MATRICS (Measurement and Treatment Research to Improve Cognition in Schizophrenia) Consensus Cognitive Battery (MCCB) [see previous results on the same participants for the longitudinal domain-scores (Juuhl-Langseth et al., 2014)]. The MCCB (Green \& Nuechterlein, 2004; Green et al., 2004; K. H. Nuechterlein et al., 2008) has been widely used in AOS samples and is found to have good test-retest reliability and a limited practice-effect (Keefe et al., 2011; Rajji et al., 2013).

The MCCB covers the following seven domains (K. H Nuechterlein \& Green, 2006): 1) Speed of Processing [Trail Making Test A (TMT-A; (War Department, 1944)], Symbol Coding (Brief Assessment of Cognition in Schizophrenia, BACS; (R. S. E. Keefe, 1999)), and Fluency (Category Fluency; (Blair, 1989)]; 2) Attention [The Continuous Performance TestIdentical Pairs (CPT-IP); (Cornblatt, Risch, Faris, Friedman, \& Erlenmeyer-Kimling, 1988)]; 3) Working Memory [Spatial Span (The Wechsler Memory Scale, SS-WMS; (Wechsler, 1997)) and Letter Number Span (The University of Maryland Letter Number Span test, LNS; (Gold, Carpenter, Randolph, Goldberg, \& Weinberger, 1997))]; 4) Verbal Learning [The revised Hopkins Verbal Learning Test (HVLT-R, immediate recall;(Brandt, 2001))]; 5) Visual 
Learning [The revised Brief Visuospatial Memory Test (BVMT-R; (Benedict, 1997)]; 6) Reasoning/Problem Solving [The Mazes Test (Neuropsychological Assessment Battery, NAB; (White, 2003))]; and 7) Social Cognition [The Managing Emotions part of the MayerSalovey-Caruso Emotional Intelligence Test (MSCEIT; (Mayer, 2002)]. In addition, a composite sum score was calculated using the arithmetic average of the first six domains (the average T-score across domains). At the time of neurocognitive assessments of patients in this study (2005-2008), the psychometric properties for the MSCEIT for this age group were unknown, and this test was not used.

Because there are no norms for the MCCB scores of tests respondents below the age of 20, we calculated our own T-scores with a mean of 50 and an SD of 10. General intellectual function (IQ) was assessed according to norms using the four sub-tests of the Wechsler Abbreviated Scale of Intelligence (WASI) (Vocabulary, Similarities, Block Design and Matrix Reasoning) (Wechsler, 2007).

\section{Statistical analyses}

All analyses were performed using SPSS Statistics (version 20) or STATA 14.0 software. For technical reasons a few participants (two patients at T1, four at T2 and two at T3, and six healthy controls at T1, two at T2 and none at T3) were unable to perform every test of the battery included in the composite score. Thus, there were some randomly missing data points. To account for missing data and confounding variables, all analyses were performed with a linear mixed model that has been recommended for repeated measures (Gueorguieva \& Krystal, 2004). The method has been found to preserve sample size in small longitudinal psychological studies despite missing data, an advantage over ANOVA, and provide similar measures of significance (Muth et al., 2016). 
To estimate differences between the groups over the entire follow-up period (i.e. baseline, T2 and T3) for cognitive composite scores as outcome and control for repeated measurements, we used linear mixed models with an unstructured covariance matrix. Time (measured in years after inclusion), group and time-by-group interaction were fixed effects in all models. All models included random intercept and a random effect for time. Based on the linear mixed model, we estimated mean values with $95 \%$ confidence intervals $(\mathrm{CI})$ for the three time points (baseline, T2 and T3) for each group. We also estimated the mean group changes from baseline to two years (Figure 1).

To identify risk factors of change in cognitive composite scores over time in the patient group, linear mixed models analyses were performed. All models included fixed effects for time as a continuous variable. The following clinical variables at baseline were considered for inclusion: in DUP, in the PANSS (positive, negative and general) baseline scores, in suicide attempts, in Split-GAF (symptoms and function), in remission and in hospitalizations (number of times and total weeks). Any variable with a $p<.15$ from the univariable analysis were included as fixed factors in the multivariable model. A manual backward stepwise elimination procedure using a multivariable regression model was performed to identify independent risk factors. In all models a random intercept and random effect for time was included, and an unstructured covariance matrix were used. Multivariate analyses were preceded by estimation of correlation between risk factors.

\section{Results}

Our findings for the cognitive composite score in the EOS group and the HC group over the three assessments, from baseline to the two-year follow-up, are illustrated in Figure 1 and Table 2. Analyses with a linear mixed model showed a stable significant effect of group on 
the longitudinal composite scores (regression coeff. for group $-9.7695 \% \mathrm{CI}(-12.1$ to -7.4$)$, $\mathrm{p}<.001)$ ), indicating that the mean difference between the groups were far apart at all time points (figure 1). After two years, no statistically significant reduction in the composite score was found within or between the two groups (mean between group change: -0.20 95\% CI (2.00 to 1.59$), p=0.826)$. IQ measured at baseline was identified as the only confounding factor. When adjusting for the confounding effect of IQ, the effect between the two groups changed in direction (adjusted mean between group change: $0.0995 \%$ CI (-1.67 to 1.87)), meaning that the controls experienced a larger change in the composite score compared to patients. The difference was still not statistically significant.

\section{Figure 1}

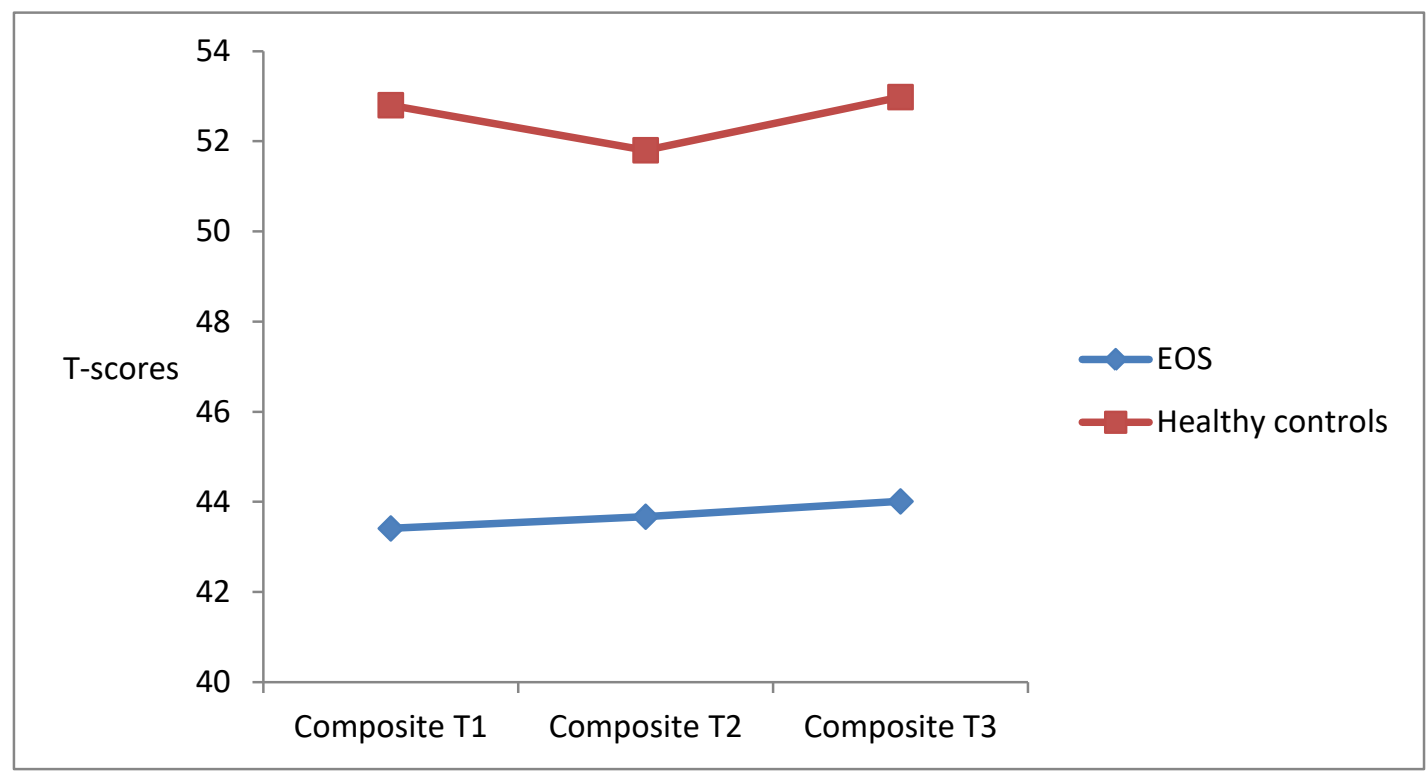

Table 2 Observed values at baseline and estimated values at follow up for the Composite scores

\begin{tabular}{|l|l|l|l|l|l|l|l|l|}
\hline & $\mathrm{n}$ & Mean & $\mathrm{n}$ & Mean & $\mathrm{n}$ & Mean & Mean & Mean \\
\hline
\end{tabular}




\begin{tabular}{|l|l|l|l|l|l|l|l|l|}
\hline & & $\begin{array}{l}\text { value at } \\
\text { baseline } \\
(\mathrm{SD})\end{array}$ & $\begin{array}{l}\text { value at } \\
\text { year 1 } \\
(95 \% \mathrm{CI})\end{array}$ & $\begin{array}{l}\text { value at } \\
\text { year 2 } \\
(95 \% \mathrm{CI})\end{array}$ & $\begin{array}{l}\text { change: } \\
\text { Year } 2 \\
\text { minus } \\
\text { baseline } \\
(95 \% \mathrm{CI})\end{array}$ & $\begin{array}{l}\text { between } \\
\text { group change } \\
(95 \% \mathrm{CI}) ; \mathrm{p}- \\
\text { value }\end{array}$ \\
\hline Patients & 29 & $43.4(5.9)$ & 18 & $\begin{array}{l}42.5(40.6 \\
\text { to } 44.5)\end{array}$ & 18 & $\begin{array}{l}42.1(39.9 \\
\text { to } 44.4)\end{array}$ & $\begin{array}{l}-0.86(-2.35 \\
\text { to } 0.64)\end{array}$ & $\begin{array}{l}-0.20(-2.00 \\
\text { to } 1.59) ; \\
0.826\end{array}$ \\
\hline Healthy & 67 & $52.8(5.2)$ & 41 & $\begin{array}{l}52.4(51.1 \\
\text { to 53.7) }\end{array}$ & 40 & $\begin{array}{l}52.1(50.6 \\
\text { to 53.5) }\end{array}$ & $\begin{array}{l}-0.66(-1.65 \\
\text { to } 0.33)\end{array}$ & \\
\hline
\end{tabular}

To identify possible risk factors of the longitudinal composite score, linear mixed model analyses were performed. The univariable analyses did not detect a relationship between Split-GAF, remission or hospitalizations (times or length) and the composite score, and were thus not included in the multiple regression analysis.

From the univariable analysis DUP, all the PANSS variables (positive, negative and general), and the number of suicide attempts were identified as possible risk factors of the longitudinal composite score $(\mathrm{p}<.15)$. However, since the PANSS (positive, negative, and general) baseline scores were strongly correlated, only PANSS general baseline score were included in multivariable analysis, as it was identified as the strongest risk factor. Multiple regression analysis showed that PANSS general and suicide attempt history at baseline were the only risk factors that significantly predicted the longitudinal cognitive course. The results are shown in Table 3.

Table 3 Estimated risk factors of change in Cognitive Composite Score over time in EOS patients using multiple linear mixed models 
$95 \% \mathrm{CI}$

\begin{tabular}{lcccccc} 
Parameter & Estimate & $S E$ & $d f$ & $t$ & Lower & Upper \\
\hline Intercept & 53.16 & 3.16 & 53.0 & 16.80 & 46.82 & 59.51 \\
$\begin{array}{l}\text { PANSS } \\
\text { general }\end{array}$ & -0.26 & 0.09 & 48.8 & $-2.92^{* *}$ & -0.44 & -0.08 \\
$\begin{array}{l}\text { Suicide } \\
\text { attempts }\end{array}$ & -2.16 & 1.01 & 26.6 & $-2.15^{*}$ & -4.23 & -0.09 \\
Time & -0.99 & 0.52 & 15.9 & -1.89 & -2.09 & 0.12 \\
\hline
\end{tabular}

$* * \mathrm{p}<.01, * \mathrm{p}<.05$

When comparing the dropouts (attended solely at T1) with the ones who continued to T2 and/or T3, the EOS dropouts were more compromised with regard to baseline cognitive functioning (composite scores) than the patients who remained in the study $(\mathrm{t}(27)=3.3, \mathrm{p}<.01)$. These differences did not appear in the control group.

\section{Discussion}

The mixed model supported what is previously reported in the Early-onset Study (JuuhlLangseth et al., 2014), as well as other longitudinal studies (Frangou et al., 2008; Jepsen, Fagerlund, Pagsberg, Christensen, Hilker, et al., 2010), namely that there seems to be a deficit in the cognitive function in EOS compared to controls, and that the course is relatively stable over a period of two years. Since the control group functioned above average in IQ, this might have affected the results. When adjusting for IQ in the analyses, the controls did experience a larger cognitive change compared to patients. However, the difference was not significant. Furthermore, the EOS dropouts had larger cognitive deficits at baseline than the ones that stayed in the study, which could imply a different cognitive course for these patients. Nevertheless, a stable global cognitive course indicates that degeneration, defined as a 
progressive neurodegenerative process after illness onset, does not occur in EOS within the few first years of diagnosis, a finding which is consistent with most previous studies (Frangou et al., 2008; Jepsen, Fagerlund, Pagsberg, Christensen, Hilker, et al., 2010), but not all (Oie et al., 2010).

We found that a higher amount of general symptoms (PANSS) at baseline significantly predicted a deteriorated longitudinal composite score in EOS. In the separate univariate analyses, both positive symptoms (PANSS) and negative symptoms (PANSS) predicted the cognitive course. However, they both lost their predictive value in the multiple regression analyses. Our findings are in line with previous research from AOS that detects no significant long-term relationship between positive/negative symptoms and cognition (Harvey et al., 2006; Rund et al., 2015; Rund et al., 2004), thus indicating a continuity between EOS and schizophrenia with later onset. Like us, Wozniak et al. (2008) found no significant relationship between psychotic symptoms and cognition in adolescent schizophrenia. Yet, their study did not report an evaluation of general symptoms (Wozniak et al., 2008). The general psychopathology scale of the PANSS measures the severity of the schizophrenic illness (Kay et al., 1987). While the positive and negative scales measure the amount of typical psychotic symptoms, the general scale includes 16 non-specific psychiatric symptoms, i.e. depression, anxiety, guilt feeling and social avoidance. In our study, we examined the total score and not the symptoms separately. Our study therefore gives no indication of the relative effect of specific symptoms included in the scale. However, our findings suggest that general symptoms are a more potent predictor of the neurocognitive course in EOS than the psychotic symptoms. This may imply that cognitive deterioration is influenced by a strong affective response to the illness, rather than a result of irrational or psychotic symptoms in and of themselves. 
As with later onset schizophrenia, the youths with schizophrenia-spectrum disorders have an increased risk of suicide within a year after the onset of psychosis (Sanchez-Gistau et al., 2013), particularly if they have a history of depression and previous suicide attempts (Melle, 2013). Our results indicated that a history of suicide attempts was related to cognitive deterioration. An association between suicidality and neurocognitive functioning in AOS has also been reported in some studies, suggesting a relationship between hopelessness, a greater insight into one's own illness and a higher cognitive functioning on the one side, and a higher risk of suicidality on the other (Delaney et al., 2012; Kim et al., 2003), while other studies report no such associations (Potkin et al., 2003; Zoghbi et al., 2014). To the best of our knowledge, no previous research has investigated the relationship between suicide attempts and long-term cognition in EOS. Hence, our study is the first to demonstrate that a history of suicide attempts at baseline predict a worsened neurocognitive course in EOS. This relationship should be understood in the context of general symptoms, because both suicidal ideation and suicide attempts most likely interact with several symptoms on the general scale, i.e. depression and social avoidance. As suggested by Fialko et al. (2006), suicide attempts in psychosis appear to be caused by an entire range of general symptoms, rather than by the psychotic symptoms alone. Those who suffer from psychosis are often met with stigma, pessimism and exclusion in society (van Os \& Kapur, 2009), consequently adding an extra burden to the illness that may affect both general symptoms and suicidality. Furthermore, suicide attempts have been associated with impulsivity as measured by neurocognitive tests (Wang et al., 2014; Wu et al., 2009). Impulsivity is often also connected to cognitive deterioration (Arce \& Santisteban, 2006), and both suicide attempts and impulsivity may indicate a higher level of general symptoms. Our findings of a relationship between a history of suicide attempts at baseline and a deteriorated global cognition in EOS after two years 
should be replicated in studies with longer follow-up periods, to examine whether the cognitive worsening endures. Still, the high rate of suicidality in schizophrenia strongly suggests that suicidal ideation and history need to be determined, and protective measures have to be taken while planning the inpatient and outpatient treatment of these patients.

Our study indicated a stable longitudinal cognitive course in EOS, but also that high PANNS general symptoms and number of suicide attempts at baseline predicted cognitive deterioration, which may indicate heterogeneity within the EOS group. Thus, there may be a subgroup of patients who deteriorates over time due to higher levels of general symptoms and suicidality. However, our sample size is too small to isolate such a subgroup, but the hypothesis should be subject to investigation in future research with larger sample sizes.

Like a majority of studies from AOS (Rapp et al., 2013; Rund, 2014; Rund et al., 2015), we found no significant influence of DUP on long-term cognition in EOS, thus there were no signs of neurotoxicity at least in the timeframe measured. In adolescence, the brain matures extensively, and one could assume that a longer DUP would have a more severe impact on cognition in this time period. Nonetheless, we detected no indication of DUP being more critical in adolescent psychosis than in adult psychosis. In line with our findings, Kravariti et al. (2003a) found no significant effect of illness duration on baseline cognitive performance in EOS. Nevertheless, the results of Fraguas et al. (2014) indicated that DUP predicts reduced long-term executive functioning in EOS. A possibility is that DUP affects executive functions more severely than other cognitive domains, and by evaluating composite scores in our study the impact was diffused.

Furthermore, our study did not reveal a significant relationship between Split-GAF and cognition, or between remission before baseline and the longitudinal composite score. In an adult sample, Rund et al. (2015) found that stable remission without relapse in the first 
year predicted a better cognitive course, implying that patients with a stable remission respond better to treatment, and have good prognosis and cognitive trajectories. A possible cause for the divergent results is that remission in a younger population is more unstable, and therefore not a good predictor of cognitive development in EOS. In our study, we defined remission by the disappearance of psychotic symptoms for at least seven days, which is short. It has previously been suggested that six months is an indication of clinical remission via the PANSS (Andreasen et al., 2005; Opler, Yang, Caleo, \& Alberti, 2007). Even though 70\% of the patients in our EOS group were in remission over a period of 8-17 weeks, none of the patients were symptom free for more than five months before baseline. As a result, remission in our group seemed quite unstable, and would have been nonexistent with a stricter definition of remission (six months).

The present study found no significant relationship among the number of hospitalizations, length of stay in institutions and longitudinal cognition. Even though longterm institutional stays have decreased markedly, hospitalizations occur, often caused by severe psychosis. A recent review concludes that there are minimal indications of cognitive changes due to institutionalizations; whether long or short (Harvey, Loewenstein, \& Czaja, 2013), which is supported by our findings.

A limitation of our study is the modest sample size, hence opening for the possibility that a larger sample might reveal more significant associations between clinical variables and long-term cognition. However, our sample size is not particularly smaller than those of other EOS studies with a similar attrition rate (Fraguas et al., 2014; Kravariti et al., 2003a, 2003b; Wozniak et al., 2008). Also, the drop-out of patients and missing data represents a limitation. In longitudinal studies, the ideal is to have a complete set of data and no drop-outs, but this has been difficult to achieve. The mixed model has been recommended over repeated 
measures ANOVA in longitudinal psychological studies with small sample sizes, because of its ability to accommodate missing data points (Krueger \& Tian, 2004; Muth et al., 2016). Still, results based on missing data should always be interpreted with caution. As already mentioned, the dropouts in the EOS group had more profound cognitive deficits than the ones who continued, which raises questions about the generalizability of the results. However, in relation to the risk factors measured at $\mathrm{T} 1$, the EOS patients at baseline were clinically very similar to those who participated at $\mathrm{T} 2$ and $\mathrm{T} 3$, both in diagnoses, symptoms and global functioning. Moreover, only one of the patients who had attempted to commit suicide before baseline left the study, thereby indicating that our findings were minimally influenced by drop-outs.

A further limitation concerns medication effect. Approximately $70 \%$ of the patients received second-generation anti-psychotics, and we had limited control over medication effects in relation to cognitive achievements. In one study, longer exposure to medication has been reported to predict a lower level of performance in aspects of attention, psychomotor processing speed and spatial working memory (Kravariti et al., 2003a). However, previous analyses of the current material did not detect a relationship between medication and cognitive performance (Juuhl-Langseth et al., 2014).

A final limitation concerns the measurement of clinical variables, especially the unreliable assessment of suicide attempts that was solely based on the patient's self-reports. It is difficult to obtain reliable measures concerning suicide attempts. However, the clinical psychologists involved in the assessments attended regular diagnostic consensus meetings led by well-experienced clinical researchers throughout the entire assessment process, to help ensure inter-rater reliability. 
The strengths of the present study are the use of a standardized comprehensive neurocognitive test battery, the MCCB, which facilitate comparisons in future research. Because of the low frequency of EOS, the patient group provides valuable information about baseline cognitive functioning, in combination with a minimized effect of confounding variables associated with chronicity. Furthermore, the longitudinal follow-up studies are of great importance in detecting neurocognitive trajectories in schizophrenia (Bora, Yucel, \& Pantelis, 2010; Gur et al., 2014; Rund, 1998).

\section{Conclusions}

The EOS patients followed much the same stable cognitive course as found in schizophrenia patients with a later onset, thus confirming continuity between early-onset and adult-onset schizophrenia. Despite the small sample size, clinical characteristics in the early illness period, such as DUP, remission and hospitalization, did not seem to influence the neurocognitive course. Our findings indicate that higher scores of general symptoms, as well as suicide attempt history, predict a deteriorated cognitive course, and should be subject to specific attention in the evaluation and treatment of patients with early-onset psychosis.

\section{Acknowledgements}

The authors wish to thank Rune Thormodsen who contributed to the Early-onset study and Pål Ulleberg for the statistical support.

\section{Financial support}

This work was supported by the South-Eastern Norway Regional Health Authority (grant number 2004-259 and 2006-186 to Bjørn Rishovd Rund). The funding source had no role in 
the collection, analysis and interpretation of data, in the writing of the report, or in the decision to submit the paper for publication.

\section{Conflict of interest}

No conflicts declared.

\section{Ethical standards}

The authors assert that all procedures contributing to this work comply with the ethical standards of the relevant national and institutional committees on human experimentation and with the Helsinki Declaration of 1975, as revised in 2008. 


\section{References}

Andreasen, N. C., Carpenter, W. T., Jr., Kane, J. M., Lasser, R. A., Marder, S. R., \& Weinberger, D. R. (2005). Remission in schizophrenia: proposed criteria and rationale for consensus. Am J Psychiatry, 162(3), 441-449. doi:10.1176/appi.ajp.162.3.441

Arango, C., Fraguas, D., \& Parellada, M. (2014). Differential neurodevelopmental trajectories in patients with early-onset bipolar and schizophrenia disorders. Schizophr Bull, 40 Suppl 2, S138-146. doi:10.1093/schbul/sbt198

Arce, E., \& Santisteban, C. (2006). Impulsivity: a review. Psicothema, 18(2), 213-220.

Bagney, A., Dompablo, M., Santabarbara, J., Moreno-Ortega, M., Lobo, A., Jimenez-Arriero, M. A., . . Rodriguez-Jimenez, R. (2015). Are negative symptoms really related to cognition in schizophrenia? Psychiatry Res, 230(2), 377-382. doi:10.1016/j.psychres.2015.09.022

Barder, H. E., Sundet, K., Rund, B. R., Evensen, J., Haahr, U., Ten Velden Hegelstad, W., . . . Friis, S. (2013). Ten year neurocognitive trajectories in first-episode psychosis. Front Hum Neurosci, 7, 643. doi:10.3389/fnhum.2013.00643

Benedict, R. H. B. (1997). Brief Visuospatial Memory Test—Revised. Odessa, Fla: Psychological Assessment Resources, Inc. .

Blair, J. R., Spreen, O. (1989). Predicting premorbid IQ: a revision of the National Adult Reading Test. Clin Neuropsychol., 3, 129-136.

Bombin, I., Mayoral, M., Castro-Fornieles, J., Gonzalez-Pinto, A., de la Serna, E., RapadoCastro, M., . . . Arango, C. (2013). Neuropsychological evidence for abnormal neurodevelopment associated with early-onset psychoses. Psychol Med, 43(4), 757768. doi:10.1017/s0033291712001535

Bora, E. (2015). Neurodevelopmental origin of cognitive impairment in schizophrenia. Psychol Med, 45(1), 1-9. doi:10.1017/S0033291714001263

Bora, E., Yucel, M., \& Pantelis, C. (2009). Cognitive functioning in schizophrenia, schizoaffective disorder and affective psychoses: meta-analytic study. Br J Psychiatry, 195(6), 475-482. doi:10.1192/bjp.bp.108.055731

Bora, E., Yucel, M., \& Pantelis, C. (2010). Cognitive impairment in schizophrenia and affective psychoses: implications for DSM-V criteria and beyond. Schizophr Bull, 36(1), 36-42. doi:10.1093/schbul/sbp094

Brandt, J., Benedict, R.H.B. (2001). The Hopkins Verbal Learning Test-Revised. Odessa, Fla: Psychological Assessment Resources, Inc. .

Cannon, M., Jones, P., Huttunen, M. O., Tanskanen, A., Huttunen, T., Rabe-Hesketh, S., \& Murray, R. M. (1999). School performance in Finnish children and later development 
of schizophrenia: a population-based longitudinal study. Arch Gen Psychiatry, 56(5), 457-463.

Christensen, T., Vesterager, L., Krarup, G., Olsen, B. B., Melau, M., Gluud, C., \& Nordentoft, M. (2014). Cognitive remediation combined with an early intervention service in first episode psychosis. Acta Psychiatr Scand, 130(4), 300-310. doi:10.1111/acps.12287

Cornblatt, B. A., Risch, N. J., Faris, G., Friedman, D., \& Erlenmeyer-Kimling, L. (1988). The Continuous Performance Test, identical pairs version (CPT-IP): I. New findings about sustained attention in normal families. Psychiatry Res, 26(2), 223-238.

Cuesta, M. J., Garcia de Jalon, E., Campos, M. S., Ibanez, B., Sanchez-Torres, A. M., \& Peralta, V. (2012). Duration of untreated negative and positive symptoms of psychosis and cognitive impairment in first episode psychosis. Schizophrenia Research, 141(23), 222-227. doi:10.1016/j.schres.2012.08.019

Delaney, C., McGrane, J., Cummings, E., Morris, D. W., Tropea, D., Gill, M., . . Donohoe, G. (2012). Preserved cognitive function is associated with suicidal ideation and single suicide attempts in schizophrenia. Schizophrenia Research, 140(1-3), 232-236. doi:10.1016/j.schres.2012.06.017

Dominguez, M. D., Fisher, H. L., Major, B., Chisholm, B., Rahaman, N., Joyce, J., . . Hodes, M. (2013). Duration of untreated psychosis in adolescents: ethnic differences and clinical profiles. Schizophrenia Research, 150(2-3), 526-532. doi:10.1016/j.schres.2013.08.018

Fervaha, G., Foussias, G., Agid, O., \& Remington, G. (2014). Motivational and neurocognitive deficits are central to the prediction of longitudinal functional outcome in schizophrenia. Acta Psychiatr Scand, 130(4), 290-299. doi:10.1111/acps.12289

Fialko, L., Freeman, D., Bebbington, P. E., Kuipers, E., Garety, P. A., Dunn, G., \& Fowler, D. (2006). Understanding suicidal ideation in psychosis: findings from the Psychological Prevention of Relapse in Psychosis (PRP) trial. Acta Psychiatr Scand, 114(3), 177186. doi:10.1111/j.1600-0447.2006.00849.x

Fitzgerald, D., Lucas, S., Redoblado, M. A., Winter, V., Brennan, J., Anderson, J., \& Harris, A. (2004). Cognitive functioning in young people with first episode psychosis: relationship to diagnosis and clinical characteristics. Aust N Z J Psychiatry, 38(7), 501-510. doi:10.1111/j.1440-1614.2004.01403.x

Fraguas, D., Merchan-Naranjo, J., del Rey-Mejias, A., Castro-Fornieles, J., Gonzalez-Pinto, A., Rapado-Castro, M., . . Parellada, M. (2014). A longitudinal study on the relationship between duration of untreated psychosis and executive function in earlyonset first-episode psychosis. Schizophrenia Research, 158(1-3), 126-133. doi:10.1016/j.schres.2014.06.038

Frangou, S. (2013). Neurocognition in early-onset schizophrenia. Child Adolesc Psychiatr Clin N Am, 22(4), 715-726. doi:10.1016/j.chc.2013.04.007 
Frangou, S., Hadjulis, M., \& Vourdas, A. (2008). The Maudsley early onset schizophrenia study: cognitive function over a 4-year follow-up period. Schizophr Bull, 34(1), 52-59. doi:10.1093/schbul/sbm124

Gold, J. M., Carpenter, C., Randolph, C., Goldberg, T. E., \& Weinberger, D. R. (1997). Auditory working memory and Wisconsin Card Sorting Test performance in schizophrenia. Arch Gen Psychiatry, 54(2), 159-165.

Goldberg, T. E., Burdick, K. E., McCormack, J., Napolitano, B., Patel, R. C., Sevy, S. M., . . . Robinson, D. G. (2009). Lack of an inverse relationship between duration of untreated psychosis and cognitive function in first episode schizophrenia. Schizophrenia Research, 107(2-3), 262-266. doi:10.1016/j.schres.2008.11.003

Green, M. F., \& Nuechterlein, K. H. (2004). The MATRICS initiative: developing a consensus cognitive battery for clinical trials. Schizophrenia Research, 72(1), 1-3. doi:10.1016/j.schres.2004.09.006

Green, M. F., Nuechterlein, K. H., Gold, J. M., Barch, D. M., Cohen, J., Essock, S., . . Marder, S. R. (2004). Approaching a consensus cognitive battery for clinical trials in schizophrenia: the NIMH-MATRICS conference to select cognitive domains and test criteria. Biol Psychiatry, 56(5), 301-307. doi:10.1016/j.biopsych.2004.06.023

Gueorguieva, R., \& Krystal, J. H. (2004). Move over ANOVA: progress in analyzing repeated-measures data and its reflection in papers published in the Archives of General Psychiatry. Arch Gen Psychiatry, 61(3), 310-317. doi:10.1001/archpsyc.61.3.310

Gur, R. C., Calkins, M. E., Satterthwaite, T. D., Ruparel, K., Bilker, W. B., Moore, T. M., . . . Gur, R. E. (2014). Neurocognitive growth charting in psychosis spectrum youths. JAMA Psychiatry, 71(4), 366-374. doi:10.1001/jamapsychiatry.2013.4190

Harvey, P. D., Green, M. F., Bowie, C., \& Loebel, A. (2006). The dimensions of clinical and cognitive change in schizophrenia: evidence for independence of improvements. Psychopharmacology (Berl), 187(3), 356-363. doi:10.1007/s00213-006-0432-1

Harvey, P. D., Loewenstein, D. A., \& Czaja, S. J. (2013). Hospitalization and psychosis: influences on the course of cognition and everyday functioning in people with schizophrenia. Neurobiol Dis, 53, 18-25. doi:10.1016/j.nbd.2012.10.022

Heinrichs, R. W., \& Zakzanis, K. K. (1998). Neurocognitive deficit in schizophrenia: a quantitative review of the evidence. Neuropsychology, 12(3), 426-445.

Hoff, A. L., Sakuma, M., Wieneke, M., Horon, R., Kushner, M., \& DeLisi, L. E. (1999). Longitudinal neuropsychological follow-up study of patients with first-episode schizophrenia. Am J Psychiatry, 156(9), 1336-1341.

Holmen, A., Juuhl-Langseth, M., Thormodsen, R., Melle, I., \& Rund, B. R. (2010).

Neuropsychological profile in early-onset schizophrenia-spectrum disorders: measured with the MATRICS battery. Schizophr Bull, 36(4), 852-859.

doi:10.1093/schbul/sbn174 
Hor, K., \& Taylor, M. (2010). Suicide and schizophrenia: a systematic review of rates and risk factors. J Psychopharmacol, 24(4 Suppl), 81-90. doi:10.1177/1359786810385490

Jepsen, J. R., Fagerlund, B., Pagsberg, A. K., Christensen, A. M., Hilker, R. W., Nordentoft, M., \& Mortensen, E. L. (2010). Course of intelligence deficits in early onset, first episode schizophrenia: a controlled, 5-year longitudinal study. Eur Child Adolesc Psychiatry, 19(4), 341-351. doi:10.1007/s00787-009-0053-4

Jepsen, J. R., Fagerlund, B., Pagsberg, A. K., Christensen, A. M., Nordentoft, M., \& Mortensen, E. L. (2010). Deficient maturation of aspects of attention and executive functions in early onset schizophrenia. Eur Child Adolesc Psychiatry, 19(10), 773786. doi:10.1007/s00787-010-0126-4

Jepsen, J. R., Fagerlund, B., Pagsberg, A. K., Christensen, A. M., Nordentoft, M., \& Mortensen, E. L. (2013). Profile of cognitive deficits and associations with depressive symptoms and intelligence in chronic early-onset schizophrenia patients. Scand $J$ Psychol, 54(5), 363-370. doi:10.1111/sjop.12062

Juuhl-Langseth, M., Holmen, A., Thormodsen, R., Oie, M., \& Rund, B. R. (2014). Relative stability of neurocognitive deficits in early onset schizophrenia spectrum patients. Schizophrenia Research, 156(2-3), 241-247. doi:10.1016/j.schres.2014.04.014

Kay, S. R., Fiszbein, A., \& Opler, L. A. (1987). The positive and negative syndrome scale (PANSS) for schizophrenia. Schizophr Bull, 13(2), 261-276.

Keefe, Fox, K. H., Harvey, P. D., Cucchiaro, J., Siu, C., \& Loebel, A. (2011). Characteristics of the MATRICS Consensus Cognitive Battery in a 29-site antipsychotic schizophrenia clinical trial. Schizophrenia Research, 125(2-3), 161-168. doi:10.1016/j.schres.2010.09.015

Keefe, R. S. E. (1999). Brief Assessment of Cognition in Schizophrenia. Durham, NC: Duke University Medical Center.

Kim, C. H., Jayathilake, K., \& Meltzer, H. Y. (2003). Hopelessness, neurocognitive function, and insight in schizophrenia: relationship to suicidal behavior. Schizophrenia Research, 60(1), 71-80.

Kravariti, E., Morris, R. G., Rabe-Hesketh, S., Murray, R. M., \& Frangou, S. (2003a). The Maudsley Early-Onset Schizophrenia Study: cognitive function in adolescent-onset schizophrenia. Schizophrenia Research, 65(2-3), 95-103.

Kravariti, E., Morris, R. G., Rabe-Hesketh, S., Murray, R. M., \& Frangou, S. (2003b). The Maudsley early onset schizophrenia study: cognitive function in adolescents with recent onset schizophrenia. Schizophrenia Research, 61(2-3), 137-148.

Kravariti, E., Morris, R. G., Rabe-Hesketh, S., Murray, R. M., \& Frangou, S. (2007). Comparative profile analysis of cognitive function in recent-onset and chronic patients with adolescent-onset schizophrenia. Schizophrenia Research, 94(1-3), 240-244. doi:10.1016/j.schres.2007.05.014 
Kravariti, E., Russo, M., Vassos, E., Morgan, K., Fearon, P., Zanelli, J. W., . . Reichenberg, A. (2012). Linear and non-linear associations of symptom dimensions and cognitive function in first-onset psychosis. Schizophrenia Research, 140(1-3), 221-231. doi:10.1016/j.schres.2012.06.008

Krueger, C., \& Tian, L. (2004). A comparison of the general linear mixed model and repeated measures ANOVA using a dataset with multiple missing data points. Biol Res Nurs, 6(2), 151-157. doi:10.1177/1099800404267682

Kumra, S., \& Charles Schulz, S. (2008). Editorial: research progress in early-onset schizophrenia. Schizophr Bull, 34(1), 15-17. doi:10.1093/schbul/sbm123

Landro, N. I., Orbeck, A. L., \& Rund, B. R. (1993). Memory functioning in chronic and nonchronic schizophrenics, affectively disturbed patients and normal controls. Schizophrenia Research, 10(1), 85-92.

Mayer, J. D., Salovey, P., Caruso, D.R. (2002). Mayer-Salovey-Caruso Emotional Intelligence Test. Toronto, ON: MHS Publishers.

Mayoral, M., Zabala, A., Robles, O., Bombin, I., Andres, P., Parellada, M., . . Arango, C. (2008). Neuropsychological functioning in adolescents with first episode psychosis: a two-year follow-up study. Eur Psychiatry, 23(5), 375-383. doi:10.1016/j.eurpsy.2008.01.1420

McCarthy, J. B., Weiss, S. R., Segovich, K. T., \& Barbot, B. (2016). Impact of psychotic symptoms on cognitive functioning in child and adolescent psychiatric inpatients with severe mood disorders. Psychiatry Res, 244, 223-228.

doi:10.1016/j.psychres.2016.07.049

Meier, M. H., Caspi, A., Reichenberg, A., Keefe, R. S., Fisher, H. L., Harrington, H., . . . Moffitt, T. E. (2014). Neuropsychological decline in schizophrenia from the premorbid to the postonset period: evidence from a population-representative longitudinal study. Am J Psychiatry, 171(1), 91-101.

doi:10.1176/appi.ajp.2013.12111438

Melle, I. (2013). History of depression and previous suicide attempt predict increased risk of suicide attempt following diagnosis of first-episode psychosis. Evid Based Ment Health, 16(3), 67. doi:10.1136/eb-2013-101362

Melle, I., Larsen, T. K., Haahr, U., Friis, S., Johannesen, J. O., Opjordsmoen, S., . . . McGlashan, T. (2008). Prevention of negative symptom psychopathologies in firstepisode schizophrenia: two-year effects of reducing the duration of untreated psychosis. Arch Gen Psychiatry, 65(6), 634-640. doi:10.1001/archpsyc.65.6.634

Mesholam-Gately, R. I., Giuliano, A. J., Goff, K. P., Faraone, S. V., \& Seidman, L. J. (2009). Neurocognition in first-episode schizophrenia: a meta-analytic review.

Neuropsychology, 23(3), 315-336. doi:10.1037/a0014708

Meyer, E. C., Carrion, R. E., Cornblatt, B. A., Addington, J., Cadenhead, K. S., Cannon, T. D., . . group, N. (2014). The relationship of neurocognition and negative symptoms 
to social and role functioning over time in individuals at clinical high risk in the first phase of the North American Prodrome Longitudinal Study. Schizophr Bull, 40(6), 1452-1461. doi:10.1093/schbul/sbt235

Muth, C., Bales, K. L., Hinde, K., Maninger, N., Mendoza, S. P., \& Ferrer, E. (2016). Alternative Models for Small Samples in Psychological Research. Educational and Psychological Measurement, 76(1), 64-87. doi:10.1177/0013164415580432

Nieto, R. G., \& Castellanos, F. X. (2011). A meta-analysis of neuropsychological functioning in patients with early onset schizophrenia and pediatric bipolar disorder. J Clin Child Adolesc Psychol, 40(2), 266-280. doi:10.1080/15374416.2011.546049

Nuechterlein, K. H., \& Green, M. F. (2006). MATRICS Consensus Cognitive Battery. Los Angeles: MATRICS Assessment, Inc.

Nuechterlein, K. H., Green, M. F., Kern, R. S., Baade, L. E., Barch, D. M., Cohen, J. D., . . . Marder, S. R. (2008). The MATRICS Consensus Cognitive Battery, part 1: test selection, reliability, and validity. Am J Psychiatry, 165(2), 203-213. doi:10.1176/appi.ajp.2007.07010042

O'Connor, J. A., Wiffen, B., Diforti, M., Ferraro, L., Joseph, C., Kolliakou, A., . . David, A. S. (2013). Neuropsychological, clinical and cognitive insight predictors of outcome in a first episode psychosis study. Schizophrenia Research, 149(1-3), 70-76. doi:10.1016/j.schres.2013.06.005

Oie, M., Sundet, K., \& Rund, B. R. (2010). Neurocognitive decline in early-onset schizophrenia compared with ADHD and normal controls: evidence from a 13-year follow-up study. Schizophr Bull, 36(3), 557-565. doi:10.1093/schbul/sbn127

Oie, M., Sundet, K., \& Ueland, T. (2011). Neurocognition and functional outcome in earlyonset schizophrenia and attention-deficit/hyperactivity disorder: a 13-year follow-up. Neuropsychology, 25(1), 25-35. doi:10.1037/a0020855

Opler, M. G., Yang, L. H., Caleo, S., \& Alberti, P. (2007). Statistical validation of the criteria for symptom remission in schizophrenia: preliminary findings. BMC Psychiatry, 7, 35. doi:10.1186/1471-244X-7-35

Palmer, B. W., Dawes, S. E., \& Heaton, R. K. (2009). What do we know about neuropsychological aspects of schizophrenia? Neuropsychol Rev, 19(3), 365-384. doi:10.1007/s11065-009-9109-y

Pedersen, G., Hagtvet, K. A., \& Karterud, S. (2007). Generalizability studies of the Global Assessment of Functioning-Split version. Compr Psychiatry, 48(1), 88-94. doi:10.1016/j.comppsych.2006.03.008

Potkin, S. G., Anand, R., Alphs, L., \& Fleming, K. (2003). Neurocognitive performance does not correlate with suicidality in schizophrenic and schizoaffective patients at risk for suicide. Schizophrenia Research, 59(1), 59-66. doi:10.1016/S0920-9964(02)00159-7 
Rajji, T. K., Ismail, Z., \& Mulsant, B. H. (2009). Age at onset and cognition in schizophrenia: meta-analysis. Br J Psychiatry, 195(4), 286-293. doi:10.1192/bjp.bp.108.060723

Rajji, T. K., Voineskos, A. N., Butters, M. A., Miranda, D., Arenovich, T., Menon, M., ... Mulsant, B. H. (2013). Cognitive performance of individuals with schizophrenia across seven decades: a study using the MATRICS consensus cognitive battery. Am J Geriatr Psychiatry, 21(2), 108-118. doi:10.1016/j.jagp.2012.10.011

Rapoport, J. L., Giedd, J. N., \& Gogtay, N. (2012). Neurodevelopmental model of schizophrenia: update 2012. Mol Psychiatry, 17(12), 1228-1238.

doi:10.1038/mp.2012.23

Rapp, C., Studerus, E., Bugra, H., Aston, J., Tamagni, C., Walter, A., . . Riecher-Rossler, A. (2013). Duration of untreated psychosis and cognitive functioning. Schizophrenia Research, 145(1-3), 43-49. doi:10.1016/j.schres.2012.12.016

Remschmidt, H. (2002). Early-onset schizophrenia as a progressive-deteriorating developmental disorder: evidence from child psychiatry. J Neural Transm (Vienna), 109(1), 101-117. doi:10.1007/s007020200008

Remschmidt, H., Martin, M., Fleischhaker, C., Theisen, F. M., Hennighausen, K., Gutenbrunner, C., \& Schulz, E. (2007). Forty-two-years later: the outcome of childhood-onset schizophrenia. J Neural Transm (Vienna), 114(4), 505-512. doi:10.1007/s00702-006-0553-z

Rund, B. R. (1998). A review of longitudinal studies of cognitive functions in schizophrenia patients. Schizophr Bull, 24(3), 425-435.

Rund, B. R. (2009). Is schizophrenia a neurodegenerative disorder? Nord J Psychiatry, 63(3), 196-201. doi:10.1080/08039480902767286

Rund, B. R. (2014). Does active psychosis cause neurobiological pathology? A critical review of the neurotoxicity hypothesis. Psychol Med, 44(8), 1577-1590. doi:10.1017/S0033291713002341

Rund, B. R., Barder, H. E., Evensen, J., Haahr, U., Hegelstad, W. T., Joa, I., . . Friis, S. (2015). Neurocognition and Duration of Psychosis: A 10-year Follow-up of FirstEpisode Patients. Schizophr Bull. doi:10.1093/schbul/sbv083

Rund, B. R., Melle, I., Friis, S., Johannessen, J. O., Larsen, T. K., Midboe, L. J., . . . McGlashan, T. (2007). The course of neurocognitive functioning in first-episode psychosis and its relation to premorbid adjustment, duration of untreated psychosis, and relapse. Schizophrenia Research, 91(1-3), 132-140. doi:10.1016/j.schres.2006.11.030

Rund, B. R., Melle, I., Friis, S., Larsen, T. K., Midboe, L. J., Opjordsmoen, S., . . . McGlashan, T. (2004). Neurocognitive dysfunction in first-episode psychosis: correlates with symptoms, premorbid adjustment, and duration of untreated psychosis. Am J Psychiatry, 161(3), 466-472. 
Rund, B. R., Sundet, K., Asbjornsen, A., Egeland, J., Landro, N. I., Lund, A., . . . Hugdahl, K. (2006). Neuropsychological test profiles in schizophrenia and non-psychotic depression. Acta Psychiatr Scand, 113(4), 350-359. doi:10.1111/j.16000447.2005.00626.x

Rund, B. R., Zeiner, P., Sundet, K., Oie, M., \& Bryhn, G. (1998). No vigilance deficit found in either young schizophrenic or ADHD subjects. Scand J Psychol, 39(2), 101-107.

Sanchez-Gistau, V., Baeza, I., Arango, C., Gonzalez-Pinto, A., de la Serna, E., Parellada, M., . . . Castro-Fornieles, J. (2013). Predictors of suicide attempt in early-onset, firstepisode psychoses: a longitudinal 24-month follow-up study. J Clin Psychiatry, 74(1), 59-66. doi:10.4088/JCP.12m07632

Schaefer, J., Giangrande, E., Weinberger, D. R., \& Dickinson, D. (2013). The global cognitive impairment in schizophrenia: consistent over decades and around the world. Schizophrenia Research, 150(1), 42-50. doi:10.1016/j.schres.2013.07.009

Schimmelmann, B. G., Conus, P., Cotton, S., McGorry, P. D., \& Lambert, M. (2007). Pretreatment, baseline, and outcome differences between early-onset and adult-onset psychosis in an epidemiological cohort of 636 first-episode patients. Schizophrenia Research, 95(1-3), 1-8. doi:10.1016/j.schres.2007.06.004

Seidman, L. J., Cherkerzian, S., Goldstein, J. M., Agnew-Blais, J., Tsuang, M. T., \& Buka, S. L. (2013). Neuropsychological performance and family history in children at age 7 who develop adult schizophrenia or bipolar psychosis in the New England Family Studies. Psychol Med, 43(1), 119-131. doi:10.1017/S0033291712000773

Sheehan, D. V., Lecrubier, Y., Sheehan, K. H., Amorim, P., Janavs, J., Weiller, E., . . Dunbar, G. C. (1998). The Mini-International Neuropsychiatric Interview (M.I.N.I.): the development and validation of a structured diagnostic psychiatric interview for DSM-IV and ICD-10. J Clin Psychiatry, 59 Suppl 20, 22-33;quiz 34-57.

Teigset, C. M., Mohn, C., \& Rund, B. R. (2016). Gestational length affects neurocognition in early-onset schizophrenia. Psychiatry Res, 244, 78-85. doi:10.1016/j.psychres.2016.07.017

Thormodsen, R., Juuhl-Langseth, M., Holmen, A., \& Rishovd Rund, B. (2012). Visual backward-masking performance in a longitudinal study of early onset schizophrenia. Psychiatry Res, 200(2-3), 153-158. doi:10.1016/j.psychres.2012.05.014

Torgalsboen, A. K., Mohn, C., \& Rishovd Rund, B. (2014). Neurocognitive predictors of remission of symptoms and social and role functioning in the early course of firstepisode schizophrenia. Psychiatry Res, 216(1), 1-5. doi:10.1016/j.psychres.2014.01.031

Townsend, L. A., \& Norman, R. M. (2004). Course of cognitive functioning in first episode schizophrenia spectrum disorders. Expert Rev Neurother, 4(1), 61-68. doi:10.1586/14737175.4.1.61 
Udal, A. H., Oygarden, B., Egeland, J., Malt, U. F., Lovdahl, H., Pripp, A. H., \& Groholt, B. (2013). Executive deficits in early onset bipolar disorder versus ADHD: impact of processing speed and lifetime psychosis. Clin Child Psychol Psychiatry, 18(2), 284299. doi:10.1177/1359104512455181

van Os, J., \& Kapur, S. (2009). Schizophrenia. Lancet, 374(9690), 635-645. doi:10.1016/S0140-6736(09)60995-8

Ventura, J., Thames, A. D., Wood, R. C., Guzik, L. H., \& Hellemann, G. S. (2010). Disorganization and reality distortion in schizophrenia: a meta-analysis of the relationship between positive symptoms and neurocognitive deficits. Schizophrenia Research, 121(1-3), 1-14. doi:10.1016/j.schres.2010.05.033

Wang, L., He, C. Z., Yu, Y. M., Qiu, X. H., Yang, X. X., Qiao, Z. X., . . Yang, Y. J. (2014). Associations between impulsivity, aggression, and suicide in Chinese college students. BMC Public Health, 14, 551. doi:10.1186/1471-2458-14-551

War Department, A. G. s. O. (Ed.) (1944). Army Individual Test Battery: Manual of Directions and Scoring, Washington, DC.

Wechsler, D. (1997). Wechsler Memory Scale (Vol. 3rd ed.). San Antonio, Tx: The Psychological Corporation. .

Wechsler, D. (2007). Wechsler Abbreviated Scale of Intelligence (WASI). Norwegian Manual Supplement. Stockholm, Sweden: Harcourt Assessment, Inc. .

White, T., Stern, R.A. (2003). Neuropsychological Assessment Battery. Lutz, FLA: Psychological Assessment Resources, Inc. .

WHO. (2010). WHO Collaborating Centre for Drug Statistics Methodology. Oslo: DDD definitions and general considerations.

Wozniak, J. R., Block, E. E., White, T., Jensen, J. B., \& Schulz, S. C. (2008). Clinical and neurocognitive course in early-onset psychosis: a longitudinal study of adolescents with schizophrenia-spectrum disorders. Early Interv Psychiatry, 2(3), 169-177. doi:10.1111/j.1751-7893.2008.00075.x

Wu, C. S., Liao, S. C., Lin, K. M., Tseng, M. M., Wu, E. C., \& Liu, S. K. (2009). Multidimensional assessments of impulsivity in subjects with history of suicidal attempts. Compr Psychiatry, 50(4), 315-321. doi:10.1016/j.comppsych.2008.09.006

Wyatt, R. J. (1991). Neuroleptics and the natural course of schizophrenia. Schizophr Bull, $17(2), 325-351$.

Yamazawa, R., Nemoto, T., Kobayashi, H., Chino, B., Kashima, H., \& Mizuno, M. (2008). Association between duration of untreated psychosis, premorbid functioning, and cognitive performance and the outcome of first-episode schizophrenia in Japanese patients: prospective study. Aust N Z J Psychiatry, 42(2), 159-165.

doi:10.1080/00048670701787537 
Zoghbi, A. W., Al Jurdi, R. K., Deshmukh, P. R., Chen da, C., Xiu, M. H., Tan, Y. L., .. . Zhang, X. Y. (2014). Cognitive function and suicide risk in Han Chinese inpatients with schizophrenia. Psychiatry Res, 220(1-2), 188-192.

doi:10.1016/j.psychres.2014.07.046 